\title{
Combination of umbilical cord mesenchymal stem cells and standard immunosuppressive regimen for pediatric patients with severe aplastic anemia
}

Yang Lan' ${ }^{1}$ Fang Liu', Lixian Chang ${ }^{1}$, Lipeng Liu', Yingchi Zhang ${ }^{1}$, Meihui Yi ${ }^{1}$, Yuli Cai', Jing Feng ${ }^{1}$, Zhibo Han ${ }^{1,2}$, Zhongchao Han ${ }^{1,2}$ and Xiaofan Zhu $^{1 *}$ (D)

\begin{abstract}
Background: Defects of bone marrow mesenchymal stem cells (BM-MSCs) in proliferation and differentiation are involved in the pathophysiology of aplastic anemia (AA). Infusion of umbilical cord mesenchymal stem cells (UCMSCS) may improve the efficacy of immunosuppressive therapy (IST) in childhood severe aplastic anemia (SAA).

Methods: We conducted an investigator-initiated, open-label, and prospective phase IV trial to evaluate the safety and efficacy of combination of allogenic UC-MSCs and standard IST for pediatric patients with newly diagnosed SAA. In mesenchymal stem cells (MSC) group, UC-MSCs were injected intravenously at a dose of $1 \times 10^{6} / \mathrm{kg}$ per week starting on the 14th day after administration of rabbit antithymocyte globulin (ATG), for a total of 3 weeks. The clinical outcomes and adverse events of patients with UC-MSCs infusion were assessed when compared with a concurrent control group in which patients received standard IST alone.

Results: Nine patients with a median age of 4 years were enrolled as the group with MSC, while the data of another 9 childhood SAA were analysed as the controls. Four (44\%) patients in MSC group developed anaphylactic reactions which were associated with rabbit ATG. When compared with the controls, neither the improvement of blood cell counts, nor the change of T-lymphocytes after IST reached statistical significance in MSC group (both $p>0.05)$ and there were one (11\%) patient in MSC group and two (22\%) patients in the controls achieved partial response (PR) at 90 days after IST. After a median follow-up of 48 months, there was no clone evolution occurring in both groups. The 4-year estimated overall survival (OS) rate in two groups were both $88.9 \% \pm 10.5 \%$, while the 4year estimated failure-free survival (FFS) rate in MSC group was lower than that in the controls $(38.1 \% \pm 17.2 \%$ vs. $66.7 \% \pm 15.7 \%, p=0.153)$.

Conclusions: Concomitant use of IST and UC-MSCs in SAA children is safe but may not necessarily improve the early response rate and long-term outcomes. This clinical trial was registered at ClinicalTrials.gov, identifier: NCT0221 8437 (registered October 2013).
\end{abstract}

Keywords: Child, Immunosuppressive therapy, Mesenchymal stem cell, Severe aplastic anemia, Umbilical cord

\footnotetext{
* Correspondence: xfzhu@ihcams.ac.cn

'State Key Laboratory of Experimental Hematology, National Clinical Research Center for Blood Diseases, Institute of Hematology \& Blood Diseases Hospital, Chinese Academy of Medical Sciences \& Peking Union Medical College, 288 Nanjing Road, Heping District, Tianjin 300020, China

Full list of author information is available at the end of the article
}

(c) The Author(s). 2021 Open Access This article is licensed under a Creative Commons Attribution 4.0 International License, which permits use, sharing, adaptation, distribution and reproduction in any medium or format, as long as you give appropriate credit to the original author(s) and the source, provide a link to the Creative Commons licence, and indicate if changes were made. The images or other third party material in this article are included in the article's Creative Commons licence, unless indicated otherwise in a credit line to the material. If material is not included in the article's Creative Commons licence and your intended use is not permitted by statutory regulation or exceeds the permitted use, you will need to obtain permission directly from the copyright holder. To view a copy of this licence, visit http://creativecommons.org/licenses/by/4.0/ The Creative Commons Public Domain Dedication waiver (http://creativecommons.org/publicdomain/zero/1.0/) applies to the data made available in this article, unless otherwise stated in a credit line to the data. 


\section{Background}

Severe aplastic anemia (SAA) is a potentially fatal disease characterized by hypoplastic or fatty bone marrow (BM), with peripheral blood (PB) pancytopenia [1]. A good deal of evidence have indicated that immune-mediated $\mathrm{T}$ cell destruction of hematopoietic stem cells (HSCs) is involved in the pathogenesis of acquired aplastic anemia (aAA) [2, 3]. Furthermore, the number of circulating regulatory $\mathrm{T}$ cells (Tregs) is generally decreased in patients with aAA [4-6]. For SAA, hematopoietic stem cell transplantation (HSCT) from a matched sibling donor is still the first-line treatment nowadays, however, due to lack of human leukocyte antigen (HLA)-compatible donors, immunosuppressive therapy (IST) with antithymocyte globulin (ATG) and cyclosporine (CsA) is also widely used in clinical practice for its potential role in young patients [7] and older patients [3]. However, the efficacy of IST is limited due to lack of response, relapse, and clonal evolution [8]. The early response rate of standard IS regimen in childhood SAA (40-50 days after ATG treatment) is correlated with long-term efficacy.

Mesenchymal stem cells (MSCs) are plastic-adherent, characterized by expression of cell surface antigens (CD105, CD73, and CD90), and lack of CD34, CD45, CD14 or CD11b, CD79 $\alpha$ or CD19 and HLA-DR surface molecules. As essential components of bone marrow microenvironment, they can support HSCs growth, and with the potential of differentiating in vitro into adipocytes, osteoblasts, and chondroblasts [9-11]. They are capable of modulating the activity of immune cells such as T cells, B cells, natural killer cells, and dendritic cells [12]. The sources of MSCs are various and they can be obtained from various tissues, including BM, dental pulp tissue, adipose tissue, amniotic fluid, and umbilical cord tissue [13-16]. It has been demonstrated that defects of BM-MSCs in proliferation and differentiation play a pivotal role in the pathophysiology of AA [17]. Nowadays, with the deep research on MSCs, the clinical application of MSCs which aims to restore the BM hematopoietic microenvironment, has provided researchers with a new treatment model for AA. Several studies had suggested that treatment with MSCs may be a feasible and effective therapeutic option for AA patients [18, 19]. Nevertheless, the application of MSCs limited to childhood SAA was rare.

Umbilical cord mesenchymal stem cells (UC-MSCs), which are isolated from healthy human umbilical cord tissue, may be ideal source of MSCs due to their abundant supply, painless collection procedures, and great expansion ability. In our previous study, a child with a 4-year history of SAA was administrated with cultureexpanded allogenic UC-MSCs after the IST of cyclophosphamide $(30 \mathrm{mg} / \mathrm{kg} /$ day $\times 4$ days $)$ and CsA $(5 \mathrm{mg} / \mathrm{kg} /$ day). The patient reaches transfusion independence now and no serious side effect occurs during or after the infusion of UC-MSCs. It has illustrated that infusion of UC-MSCs may improve the efficacy of IS therapy in childhood SAA. To assess the safety and efficacy of UCMSCs infusion for pediatric patients with SAA, we further conducted an investigator-initiated, open-label, and prospective phase IV clinical trial.

\section{Methods \\ Study population}

Patients aged between 1 month to 18 years with newly diagnosed SAA were consecutively recruited from October 2013 to October 2014 at the Institute of Hematology and Blood Diseases Hospital (China). SAA was defined as the BM cellularity $<25 \%$ (or $25-50 \%$ with $<30 \%$ residual haematopoietic cells) and at least two of the following three criteria: absolute neutrophil count $($ ANC) $<$ $0.5 \times 10^{9} / \mathrm{L}$, pre-transfusion platelet (PLT) count $<20 \times$ $10^{9} / \mathrm{L}$, or pre-transfusion absolute reticulocyte count $\left(\right.$ ARC) $<20 \times 10^{9} /$ L. Very severe aplastic anemia (vSAA) was considered adopting the same criteria, with ANC < $0.2 \times 10^{9} / \mathrm{L}[20,21]$. Patients underwent complete medical history and physical examination, routine cytogenetic analysis, mitomycin $\mathrm{C}$ testing, comet assay, and next-generation sequencing methods to exclude inherited bone marrow failure syndrome such as Fanconi anemia, Diamond Blackfan anemia and dyskeratosis congenital. Subjects with a HLA-matched sibling donor for immediate HSCT were also excluded. Other eligibility criteria encompassed adequate hepatic and renal functions, and ECOG performance status of $\leq 2$.

The study was approved by the Ethics Committee and Institutional Review Board of Chinese Academy of Medical Sciences and Peking Union Medical College, and conducted in concordance with the Declaration of Helsinki. All legal guardians of pediatric patients signed written informed consent before participation in the trial.

\section{Study design}

This was an investigator-initiated, open-label, singlecenter and prospective phase IV trial. The study was registered at ClinicalTrials.gov, identifier NCT02218437. Eligible patients were divided into two treatment groups based on their guardians' choices. Patients in MSC group received standard IST combined with UC-MSCs, while patients as the controls received standard IST alone. Rabbit ATG (Thymoglobuline ${ }^{\circ}$, IMTIX-SANGST AT) $(3 \mathrm{mg} / \mathrm{kg} . \mathrm{d} \times 5$ days $)$ and CsA $(5 \mathrm{mg} / \mathrm{kg} . \mathrm{d})$ were administered in both groups, and only in MSC group, UCMSCs were injected intravenously at a dose of $1 \times 10^{6} / \mathrm{kg}$ per week starting on the 14th day after rabbit ATG, for a total of 3 weeks. UC-MSCs in this study were supplied free of charge by Tianjin AmCellGene Engineering Co., 
Ltd. The primary objective of this work was to investigate the tolerability and toxicities of UC-MSCs for pediatric patients with SAA. The secondary objective was to evaluate the efficacy of UC-MSCs plus standard IST in childhood SAA.

\section{Clinical evaluation and response criteria}

Participants underwent baseline evaluations that comprised a complete medical history and physical examination, blood counts and serum biochemistry; BM aspiration and biopsy; serum immunoglobulins level; percentage of $\mathrm{T}$-cell subsets in $\mathrm{PB}$; detection of paroxysmal nocturnal hemoglobinuria $(\mathrm{PNH})$ clone by flow cytometry in PB; cytogenetic and mutational analysis; and next-generation sequencing methods. Blood counts and serum biochemistry were monitored and BM aspiration and/or biopsy for morphology and cytogenetics was also performed at 40 days, 3 months and 6 months after rabbit ATG.

Hematologic response was defined as follows: complete response $(\mathrm{CR})$ was defined as ANC $>1.5 \times 10^{9}$ / L, PLT $>100 \times 10^{9} / \mathrm{L}$, and hemoglobin (HGB) normal for age (all three criteria had to be achieved); partial response (PR) was defined as transfusion independence, ANC $>0.5 \times 10^{9} / \mathrm{L}$, PLT $>20 \times 10^{9} / \mathrm{L}$, and ARC $>30 \times$ $10^{9} / \mathrm{L}$ above the baseline; and persistence of transfusion dependence or death was evidence of nonresponse (NR) [22]. Failure-free survival (FFS) was defined as the time from initiation of rabbit ATG until the date of treatment failure, relapse or death, whichever came first.

\section{Measurement of Tregs}

CD4 + CD25 + CD127dim Tregs were identified by flow cytometric analysis. CD4-peridinin chlorophyll (PerCP)-Cy5.5, CD25-phycoerythrin (PE), CD127allophycocyanin (APC), mouse IgG1-PE, and mouse IgG1-APC antibodies (BD Biosciences, Franklin Lakes, NJ, USA) were used for surface staining. Fresh ethylenediaminetetraacetic acid (EDTA) anticoagulant blood samples $(100 \mu \mathrm{L})$ were separated into 2 TruCount tubes (BD Biosciences). One tube was stained with $5 \mu \mathrm{L}$ of CD4-PerCP-Cy5.5, CD25-PE, CD127APC antibodies, while another was stained with $5 \mu \mathrm{L}$ of CD4-PerCP-Cy5.5, mouse IgG1- PE, and mouse IgG1- APC as a negative control. After incubation in the dark for $15 \mathrm{~min}$ at room temperature, cells were incubated with $450 \mu \mathrm{L}$ Optilyse C Lysing Solution (BD Biosciences) for $10 \mathrm{~min}$ at room temperature and washed three times with phosphate buffered saline (PBS). Data acquisitions were performed on a FACS CantoII flow cytometer (BD Biosciences) and analyzed by FlowJo software (TreeStar, Ashland, OR, USA).

\section{Statistical analysis}

The statistical analysis was performed utilizing IBM SPSS statistics, version 18.0.0.1 (SPSS, Chicago, IL, USA). Continuous variables were presented as the means \pm standard deviations or median (range), and categorical variables were expressed as the frequency (percentage). The Kaplan-Meier method was adopted to estimate the FFS rate. Student's t-test, Chi-square test and Log-rank test were applied to calculate the differences of subgroups. All statistical tests with $p$ values $<0.05$ were considered significant. Adverse events were graded and reported according to the CTEP Version 4.0 of the NCI Common Terminology Criteria for Adverse Events.

\section{Results}

\section{Patient characteristics}

A total of 18 participants were included in this study according to the eligibility criteria, and was divided into two subgroups. A total of nine patients with newly diagnosed SAA were regarded as the MSC group. The median age at diagnosis was 4 years (range, 1-10). The ratio of males to females was 3:6, and $7(78 \%)$ patients were diagnosed as vSAA. The median duration from diagnosis to initiation of rabbit ATG was 26 days (range, 9-159). At baseline, the median values for ANC, PLT, HGB, and ARC were $0.07 \times 10^{9} / \mathrm{L}$ (range, $0-0.36$ ), $10 \times 10^{9} / \mathrm{L}$ (range, 1-18), $76 \mathrm{~g} / \mathrm{L}$ (range, 47-117), and 5.4 $\times 10^{9} / \mathrm{L}$ (range, 2.632.8) respectively. All patients in MSC group completed three doses of allogenic UC-MSCs infusion.

Furthermore, we additionally performed an analysis of 9 pediatrics with SAA who received standard IST alone as the controls. Basically, there were well-matched demographic and clinical features at baseline between two groups (Table 1).

\section{Safety and tolerability}

All patients were available for toxicity assessment (Table 2). In general, two groups had similar incidence of side effects. When compared with the controls, the most obvious adverse event in MSC group was anaphylaxis (including drug fever). A total of 4 (44\%) patients in MSC group suffered anaphylactic reactions (three with grade 1-2 and one with grade 3), and one of them complicated with grade 2 oral mucositis. However, the anaphylactic reactions (including drug fever) were associated with rabbit ATG, which were mild and can be ameliorated with antiallergic agent. A patient with oral mucositis was with a rather low ANC after UC-MSCs infusion, which may make her more susceptible to infection. In both groups, serious infectious complications (grade $\geq 3$ ) were uncommon, which were happening in $1 / 9(11 \%)$ patients. No other severe side effects were reported during the follow-up period. 
Table 1 Baseline characteristics of patients with SAA treated with or without MSCs

\begin{tabular}{|c|c|c|c|}
\hline Characteristics & MSC Group $(n=9)$ & Control Group $(n=9)$ & $P$ \\
\hline Median age, years (range) & $4(1-10)$ & $5(3-9)$ & 0.438 \\
\hline Gender, male / female & $3 / 6$ & $5 / 4$ & 0.637 \\
\hline \multicolumn{4}{|l|}{ Type of AA } \\
\hline SAA, n (\%) & $2(22 \%)$ & $4(44 \%)$ & \multirow[t]{2}{*}{0.620} \\
\hline vSAA, n (\%) & $7(78 \%)$ & $5(56 \%)$ & \\
\hline Median duration from diagnosis to ATG treatment, days (range) & $26(9-159)$ & $39(26-179)$ & 0.281 \\
\hline Median WBC, $\times 10^{9} / \mathrm{L}$ (range) & $1.84(0.57-4.79)$ & $2.60(0.65-5.23)$ & 0.699 \\
\hline Median HGB, g/L (range) & $76(47-117)$ & $65(47-105)$ & 0.475 \\
\hline Median PLT, ×109/L (range) & $10(1-18)$ & $8(4-19)$ & 0.500 \\
\hline Median ANC, $\times 10^{9} / \mathrm{L}$ (range) & $0.07(0-0.36)$ & $0.13(0.01-0.41)$ & 0.229 \\
\hline Median $A R C, \times 10^{9} / L$ (range) & $5.4(2.6-32.8)$ & $4.5(2.2-17.0)$ & 0.587 \\
\hline Median percentage of CD3 + CD4+ T-cell lymphocytes, \% (range) & $39.6(35.7-42.9)$ & $43.2(28.4-73.0)$ & 0.401 \\
\hline Median percentage of CD3 + CD8+ T-cell lymphocytes, \% (range) & $25.6(14.1-35.1)$ & $25.8(9.4-35.2)$ & 0.885 \\
\hline 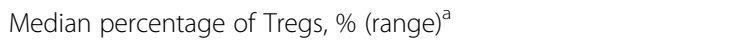 & $7.0(3.5-9.4)$ & $6.7(2.2-16.8)$ & 0.763 \\
\hline Median percentage of mature lymphocytes in BM, \% (range) & $94.1(44.5-98.5)$ & $87.9(36.2-97.7)$ & 0.306 \\
\hline
\end{tabular}

Abbreviations: $A A$ Aplastic anemia, SAA Severe aplastic anemia, $V S A A$ Very severe aplastic anemia, ATG Antithymocyte globulin, WBC White blood cell, $H G B$ Hemoglobin, PLT Platelet, ANC Absolute neutrophil count, ARC Absolute reticulocyte count, Tregs CD4 + CD25 + CD127dim regulatory T cells, BM Bone marrow

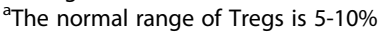

\section{Hematologic and immunologic response}

Only $1(11 \%)$ patient in MSC group and $2(22 \%)$ patients in control group achieved PR after 90 days of rabbit ATG. Figure 1 showed the blood cell counts of two groups before treatment, at 40 days and 90 days after rabbit ATG. The increase of PLT levels in MSC group was higher than that in the controls. However, two-factor repeated- measures analysis of variance revealed that improvement of PLT between two groups was of no statistical significance $(p=0.192)$. Meanwhile, there was no significant difference in escalation of ANC $(p=0.532)$, HGB $(p=0.450)$ or ARC ( $p=0.313)$ between two groups.

After 40 days of the initiation of rabbit ATG, the percentage of CD3 + CD4+ T-cell lymphocytes in both groups and

Table 2 Most common adverse events irrespective of attribution

\begin{tabular}{|c|c|c|c|c|}
\hline \multirow[t]{2}{*}{ Adverse Event } & \multicolumn{2}{|l|}{ MSC Group $(n=9)$} & \multicolumn{2}{|c|}{ Control Group $(n=9)$} \\
\hline & Grade $1 / 2$ No. (\%) & Grade 3/4 No. (\%) & Grade $1 / 2$ No. (\%) & Grade $3 / 4$ No. (\%) \\
\hline Hepatotoxicity & 0 & 0 & 0 & 0 \\
\hline Renal failure & 0 & 0 & 0 & 0 \\
\hline Nausea & 0 & 0 & 0 & 0 \\
\hline Diarrhea & 0 & 0 & 0 & 0 \\
\hline Oral mucositis & $1(11)$ & 0 & 0 & 0 \\
\hline Arrythmia & 0 & 0 & 0 & 0 \\
\hline Heart failure & 0 & 0 & 0 & 0 \\
\hline Hypertension & 0 & 0 & 0 & 0 \\
\hline Pericarditis & 0 & 0 & 0 & 0 \\
\hline Peripheral neuropathy & 0 & 0 & 0 & 0 \\
\hline Infections & 0 & $1(11)$ & 0 & $1(11)$ \\
\hline Anaphylaxis (including drug fever) & $3(33)$ & $1(11)$ & 0 & 0 \\
\hline Local phlebitis & 0 & 0 & 0 & 0 \\
\hline Fatigue & 0 & 0 & 0 & 0 \\
\hline Headache & 0 & 0 & 0 & 0 \\
\hline Fingernail changes & 0 & 0 & 0 & 0 \\
\hline
\end{tabular}




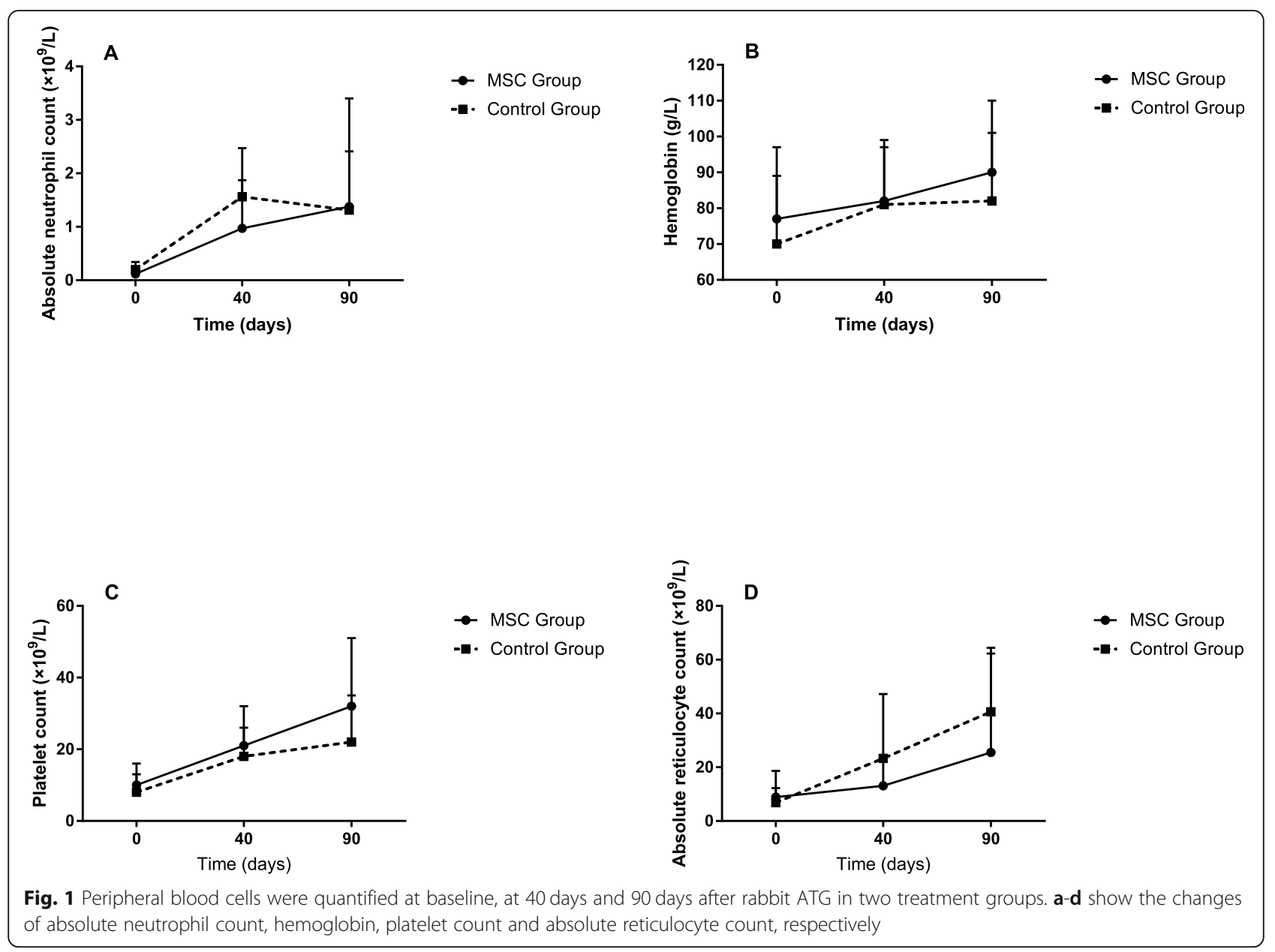

CD4 + CD25 + CD127dim Tregs in the controls tended to decrease, while the percentage of CD3 + CD8+ T-cell lymphocytes in both groups and Tregs in MSC group tended to increase (Fig. 2). However, there was no statistically significant change in the percentage of CD3 + CD4+ $(p=0.190)$, $\mathrm{CD} 3+\mathrm{CD} 8+(p=0.875)$ or $\mathrm{CD} 4+\mathrm{CD} 25+\mathrm{CD} 127 \mathrm{dim}(p=$ $0.165)$ lymphocytes after treatment between two groups.

\section{Long-term outcomes}

For all patients, the follow-up endpoint was April 13th, 2018. The median follow-up was 48 months (range, 5-
54). One patient in MSC group died of serious infection after 5 months of treatment, while one patient in control group died of intracranial hemorrhages after 7 months of treatment. Both of them were vSAA patients. Three responders (1 in MSC group and 2 in control group) who achieved PR after 90 days of ATG were all alive at follow-up without transplantation. Treatment failure was found in 4 (44\%) patients in MSC group and 2 (22\%) patients in control group. All of these patients received HSCT as salvage treatment due to lack of response to IST. Among these patients, five children received HSCT

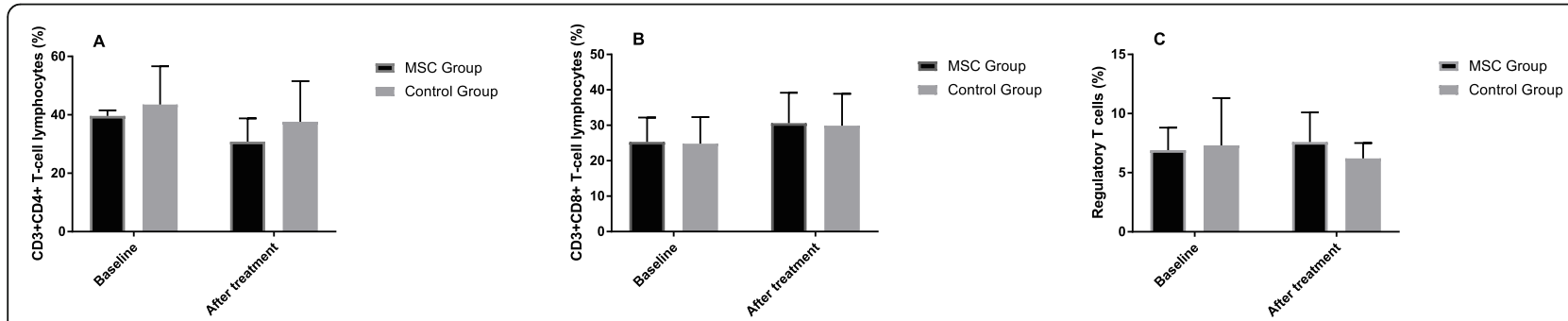

Fig. 2 The percentage of CD3 +CD4+ T-cell lymphocytes (a), CD3 + CD8+ T-cell lymphocytes (b), and CD4 + CD25 + CD127dim regulatory T cells (c) in the peripheral blood of patients performed by means of flow cytometry at baseline and after treatment 
from haploidentical family donors and one from a matched unrelated donor. In MSC group, four patients suffered treatment failure and underwent HSCT between 7 and 10 months after IST. One of them experienced grade 3 acute graft-versus-host disease (aGVHD) in intestinal, grade 2 aGVHD in skin and eye (conjunctival hyperemia with chemosis, and increased mucus secretion), and chronic graft-versus-host disease (cGVHD) in joint (joint stiffness and restricted range of motion in knee) after HSCT. At the follow-up endpoint, the patient still suffered from cGVHD in eye and was treated with oral tacrolimus and methylprednisolone. The other five patients who received HSCT were all alive without cGVHD at last follow-up. There was no clone evolution or relapse occurring in both groups at the follow-up endpoint. The 4-year estimated overall survival (OS) rate in two groups were both $88.9 \pm 10.5 \%$. The 4-year estimated FFS rate in MSC group was lower than that in the controls $(38.1 \pm 17.2 \%$ vs. $66.7 \pm 15.7 \%)$. However, there was no significant difference between two groups $(p=0.153)$ (Fig. 3).

\section{Discussion}

SAA is a rare but heterogeneous disorder. Recent studies have illustrated that haematopoietic stem/progenitor cells (HSPCs) and BM-MSCs from patients with aAA possess intrinsic deficits that contribute to their vulnerability in disease evolution [23]. Several studies have revealed the feasibility and efficacy of MSCs in improving matrix microenvironment and promoting hematopoietic recovery in AA patients who underwent HSCT [24-26]. Nevertheless, in SAA patients who lack a histocompatible sibling donor, the mainstay of treatment is still the IST. There were only few published works about combining MSCs infusion with IST for SAA treatment [18, $19,27]$. Our study is the first clinical trial to assess the efficacy and safety of UC-MSCs infusion combined with standard IS regimen in pediatric patients with SAA.

There were some noteworthy differences between our study and other works $[18,19,27]$ which applied MSCs infusion in AA patients. Firstly, the physical condition

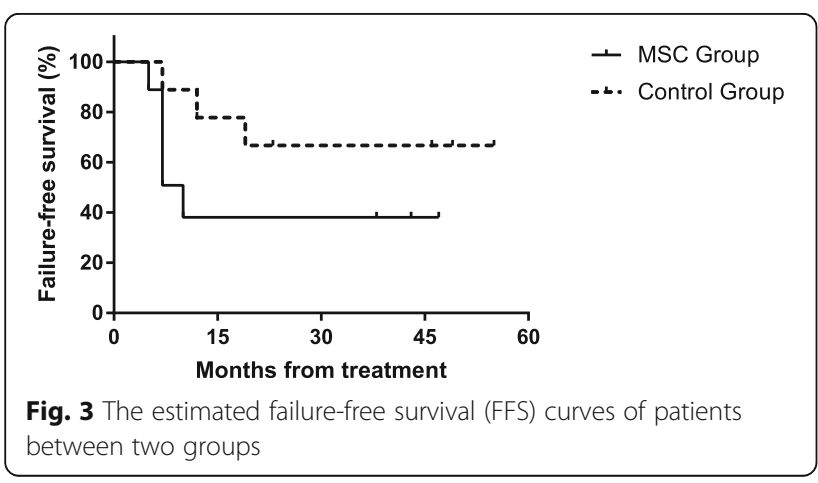

and disease background of participants was different. Our study enrolled patients aged between 1 month to 18 years with newly diagnosed SAA, while other studies recruited patients more than 16 years old with refractory or relapsed AA [18, 19, 27]. Secondly, the sources of MSCs were diverse. MSCs applied in other researches $[18,19,27]$ were from the BM of healthy donors. The aspiration of $\mathrm{BM}$ involved invasive manipulation, and the frequency and differentiation potential of BM-MSCs tapered significantly with certain factors, such as age [28]. Therefore, it is difficult to produce BM-MSCs for utilization on a large scale. By contrast, MSCs in our study were from healthy human umbilical cord tissue. They were separated, screened, passaged and cultured in vitro. To achieve large-scale production of UC-MSCs as "cell medicine", the "injection of mesenchymal stem cells (umbilical) manufacturing and verification regulation" was also formulated. Moreover, sufficient preclinical studies were conducted using guinea pigs, rabbits, and monkey models [29].

Rosenfeld et al. [30] reported that most of the patients (90\%) responded within the first 3 months, with fewer responses occurred between 3 and 6 months or after. A recent multicenter study by Pang et al. [19] showed that the hematologic response occurred almost within 3 months and the overall response rate (ORR) was $28.4 \%$. However, in our study, the ORR at 3 months was only $11 \%$ in MSC group, which was lower than that in the controls (22\%). When compared with the control group, neither the improvement of blood cell counts, nor the change of T-lymphocytes level reached statistical significance after concomitant use of MSC. It was consistent with the report of Cle et al. [27], but in contrary to the work of Xiao et al. [18] and Pang et al. [19] in which MSC infusion alone can improve the efficacy of AA patients. However, in these two researches, the proportion of nonsevere aplastic anemia (NSAA) patients were 78 and $68 \%$, respectively. Despite of limited number of patients in our study, it provided evidence that UC-MSCs infusion did not necessarily improve the early response rate of childhood SAA. A higher proportion of vSAA patients enrolled (78\%) in MSC group, delayed initiation of UC-MSCs infusion (after 2 weeks of rabbit ATG) and the low infusion frequency (a total of three doses) in our study may account for this consequence. Besides, the median ANC at baseline in the group with MSC $(0.07 \times$ $10^{9} / \mathrm{L}$ ) was approximately half of that in control group $\left(0.13 \times 10^{9} / \mathrm{L}\right)$, which could result in the lower ORR in MSC users.

The median follow-up period in our study was 48 months, which was longer than other trials $[18,19,27]$, thus it enabled us to investigate the long-term efficacy and safety of UC-MSCs utilization in children SAA. The probability of clonal evolution was also a severe adverse 
event reported in SAA patients, that is, the development of myelodysplastic syndrome (MDS) and acute myelogenous leukemia (AML). Previous study has reported that the incidence of clonal evolution is about 10 to $15 \%$ [1]. In our study, there was no clone evolution occurring in both groups at the follow-up endpoint. Moreover, the finding of OS and FFS illustrated that UC-MSCs infusion may not improve the long-term outcomes of pediatric patients with SAA. In MSC group, four (44\%) patients suffered treatment failure underwent HSCT during 7-10 months after IST, and we speculated that it may be related to the short time to response and short existence of MSCs in vivo [19]. It was consistent with the studies by Zangi et al. [31] and Ankrum et al. [32] which reported that MSCs cannot persist following infusion and long-term survival of allogeneic MSCs seems to be a major challenge. Therefore, explore new approaches to prolong the persistence of MSCs in vivo may improve the therapeutic effect of this new biological products.

A growing number of laboratory and clinical data have shown that application of MSCs is safe, but there are few articles about the safety of MSCs applied in pediatric patients. In our study, the most notable adverse event developed in MSC group was anaphylactic reaction (rabbit ATG related), however, all the events were mild and can be ameliorated with antiallergic agent. And no UC-MSCs application related death was found in all patients in MSC group. In view of this, UC-MSCs utilization may be well tolerated and safe in childhood SAA.

For some reasons, combination of allogenic UC-MSCs on top of IST was not a conventional treatment for pediatric patients with newly diagnosed SAA in clinical practice. Thus, it was difficult to recruit eligible patients for this study. Allowing for the small sample size of our study and the obvious heterogeneity of enrolled patients, some of the results may not be representative and a prospective study with larger sample size which adopt different doses of UC-MSCs may be necessary.

\section{Conclusions}

This study has preliminarily demonstrated the safety and efficacy of combination of UC-MSCs and standard IST for pediatric patients with newly diagnosed SAA. Concomitant use of IST and UC-MSCs in SAA children is safe but may not necessarily improve the early response rate and long-term outcomes.

\footnotetext{
Abbreviations

BM-MSCs: Bone marrow mesenchymal stem cells; AA: Aplastic anemia; UCMSCs: Umbilical cord mesenchymal stem cells; IST: Immunosuppressive therapy; SAA: Severe aplastic anemia; MSC: Mesenchymal stem cell; ATG: Antithymocyte globulin; PR: Partial response; OS: Overall survival; FFS: Failure-free survival; BM: Bone marrow; PB: Peripheral blood; HSCs: Hematopoietic stem cells; aAA: Acquired aplastic anemia; Tregs: Regulatory T cells; HSCT: Hematopoietic stem cell transplantation;
}

CSA: Cyclosporine; HLA: Human leukocyte antigen; ANC: Absolute neutrophil count; PLT: Platelet; ARC: Absolute reticulocyte count; vSAA: Very severe aplastic anemia; PNH: Paroxysmal nocturnal hemoglobinuria; CR: Complete response; HGB: Hemoglobin; NR: Nonresponse; PerCP: Peridinin chlorophyll; PE: Phycoerythrin; APC: Allophycocyanin; EDTA: Ethylenediaminetetraacetic acid; PBS: Phosphate buffered saline; WBC: White blood cell; aGVHD: Acute graft-versus-host disease; cGVHD: Chronic graft-versus-host disease;

HSPCs: Haematopoietic stem/progenitor cells; ORR: Overall response rate; NSAA: Nonsevere aplastic anemia; MDS: Myelodysplastic syndrome;

AML: Acute myelogenous leukemia

\section{Acknowledgements}

The authors would like to sincerely thank the clinicians that entered their patients into the study and the support of Ai You Foundation.

\section{Standards of reporting}

Our study adheres to CONSORT guidelines.

\section{Authors' contributions}

$Y L$ designed the study, collected and analyzed the data, and wrote the article; FL and $L X C$ designed the study, collected the data, and reviewed the article; LpL and YCZ reviewed the article; MhY, YIC, and JF collected the data; $\mathrm{ZbH}$ contributed to the quality control of umbilical cord mesenchymal stem cells; ZcH designed the study; XfZ designed the study and reviewed the article. The authors read and approved the final manuscript.

\section{Funding}

This work was supported by the National Key Research and Development Program of China [grant No.2016YFC0901503]. The funding covered some items of examination for patients and the article-processing charges.

\section{Availability of data and materials}

The datasets used and/or analysed during the current study are available from the corresponding author on reasonable request.

\section{Ethics approval and consent to participate}

An ethical permit was obtained from the Ethics Committee and Institutional Review Board of Chinese Academy of Medical Sciences and Peking Union Medical College (guidelines of the Declaration of Helsinki). All legal guardians of pediatric patients signed written informed consent before participation in the trial. And all participants aged 16 and over provided written informed consent for participation.

\section{Consent for publication}

Written informed consent was obtained from legal guardians of pediatric patients included in this study.

\section{Competing interests}

The authors declare that they have no competing interests.

\section{Author details}

${ }^{1}$ State Key Laboratory of Experimental Hematology, National Clinical Research Center for Blood Diseases, Institute of Hematology \& Blood Diseases Hospital, Chinese Academy of Medical Sciences \& Peking Union Medical College, 288 Nanjing Road, Heping District, Tianjin 300020, China. ${ }^{2}$ National Engineering Research Center of Cell Products, Tianjin AmCellGene Engineering Co., Ltd, Tianjin 300020, China.

Received: 11 June 2020 Accepted: 19 February 2021

Published online: 27 February 2021

\section{References}

1. Scheinberg P, Young NS. How I treat acquired aplastic anemia. Blood. 2012; 120(6):1185-96.

2. Young NS, Maciejewski J. The pathophysiology of acquired aplastic anemia. N Engl J Med. 1997:336(19):1365-72.

3. Young NS, Calado RT, Scheinberg P. Current concepts in the pathophysiology and treatment of aplastic anemia. Blood. 2006;108(8):250919. 
4. Solomou EE, Rezvani K, Mielke S, Malide D, Keyvanfar K, Visconte V, et al Deficient CD4+ CD25+ FOXP3+ T regulatory cells in acquired aplastic anemia. Blood. 2007;110(5):1603-6.

5. Kordasti S, Marsh J, Al-Khan S, Jiang J, Smith A, Mohamedali A, et al. Functional characterization of CD4+ T cells in aplastic anemia. Blood. 2012; 119(9):2033-43.

6. Shi J, Ge M, Lu S, Li X, Shao Y, Huang J, et al. Intrinsic impairment of CD4(+ )CD25(+) regulatory T cells in acquired aplastic anemia. Blood. 2012;120(8): 1624-32.

7. Dezern AE, Brodsky RA. Clinical management of aplastic anemia. Expert Rev Hematol. 2011:4(2):221-30.

8. Scheinberg P. Aplastic anemia: therapeutic updates in immunosuppression and transplantation. Hematol Am Soc Hematol Educ Program. 2012;2012: 292-300.

9. Horwitz EM, Le Blanc K, Dominici M, Mueller I, Slaper-Cortenbach I, Marini FC, et al. Clarification of the nomenclature for MSC: The International Society for Cellular Therapy position statement. Cytotherapy. 2005;7(5):3935 .

10. Dominici M, Le Blanc K, Mueller I, Slaper-Cortenbach I, Marini F, Krause D, et al. Minimal criteria for defining multipotent mesenchymal stromal cells. The International Society for Cellular Therapy position statement. Cytotherapy. 2006;8(4):315-7.

11. Dexter TM. Stromal cell associated haemopoiesis. J Cell Physiol Suppl. 1982; 1:87-94.

12. Le Blanc K, Mougiakakos D. Multipotent mesenchymal stromal cells and the innate immune system. Nat Rev Immunol. 2012;12(5):383-96.

13. Menabde G, Gogilashvili K, Kakabadze Z, Berishvili E. Bone marrow-derived mesenchymal stem cell plasticity and their application perspectives. Georgian Med News. 2009;167:71-6.

14. Kerkis I, Kerkis A, Dozortsev D, Stukart-Parsons GC, Gomes Massironi SM, Pereira LV, et al. Isolation and characterization of a population of immature dental pulp stem cells expressing OCT-4 and other embryonic stem cell markers. Cells Tissues Organs. 2006;184(3-4):105-16.

15. In't Anker PS, Scherjon SA, Kleijburg-van der Keur C, Noort WA, Claas FH, Willemze $\mathrm{R}$, et al. Amniotic fluid as a novel source of mesenchymal stem cells for therapeutic transplantation. Blood. 2003;102(4):1548-9.

16. Lu LL, Liu YJ, Yang SG, Zhao QJ, Wang X, Gong W, et al. Isolation and characterization of human umbilical cord mesenchymal stem cells with hematopoiesis-supportive function and other potentials. Haematologica. 2006;91(8):1017-26.

17. Chao YH, Peng CT, Harn HJ, Chan CK, Wu KH. Poor potential of proliferation and differentiation in bone marrow mesenchymal stem cells derived from children with severe aplastic anemia. Ann Hematol. 2010;89(7):715-23.

18. Xiao Y, Jiang Z-J, Pang Y, Li L, Gao Y, Xiao H-W, et al. Efficacy and safety of mesenchymal stromal cell treatment from related donors for patients with refractory aplastic anemia. Cytotherapy. 2013;15(7):760-6.

19. Pang Y, Xiao H-W, Zhang H, Liu Z-H, Li L, Gao Y, et al. Allogeneic bone marrow-derived mesenchymal stromal cells expanded in vitro for treatment of aplastic anemia: a multicenter phase II trial. Stem Cells Transl Med. 2017; 6(7):1569-75.

20. Camitta BM, Rappeport JM, Parkman R, Nathan DG. Selection of patients for bone marrow transplantation in severe aplastic anemia. Blood. 1975;45(3): 355-63.

21. Bacigalupo A, Hows J, Gluckman E, Nissen C, Marsh J, Van Lint MT, et al. Bone marrow transplantation (BMT) versus immunosuppression for the treatment of severe aplastic anaemia (SAA): a report of the EBMT SAA working party. Br J Haematol. 1988;70(2):177-82.

22. Subspecialty Group of $\mathrm{H}$, Society of $\mathrm{P}$, Chinese Medical Association The Editorial B, Chinese Journal of P. Recommendations for diagnosis and treatment of acquired aplastic anemia in children. Zhonghua Er Ke Za Zhi. 2014;52(2):103-6.

23. Zeng $Y$, Katsanis $E$. The complex pathophysiology of acquired aplastic anaemia. Clin Exp Immunol. 2015;180(3):361-70.

24. Fang B, Song Y, Li N, Li J, Zhao RC. Cotransplantation of haploidentica mesenchymal stem cells to reduce the risk of graft failure in a patient with refractory severe aplastic anemia. Acta Haematol. 2008;119(3):162-5.

25. Jaganathan BG, Tisato V, Vulliamy T, Dokal I, Marsh J, Dazzi F, et al. Effects of MSC co-injection on the reconstitution of aplastic anemia patient following hematopoietic stem cell transplantation. Leukemia. 2010;24(10):1791-5.

26. Wu Y, Cao Y, Li X, Xu L, Wang Z, Liu P, et al Cotransplantation of haploidentical hematopoietic and umbilical cord mesenchymal stem cells for severe aplastic anemia: successful engraftment and mild GVHD. Stem Cell Res. 2014;12(1):132-8.

27. Clé DV, Santana-Lemos B, Tellechea MF, Prata KL, Orellana MD, Covas DT, et al. Intravenous infusion of allogeneic mesenchymal stromal cells in refractory or relapsed aplastic anemia. Cytotherapy. 2015;17(12):1696-705.

28. Rao MS, Mattson MP. Stem cells and aging: expanding the possibilities. Mech Ageing Dev. 2001;122(7):713-34.

29. Wang Y, Han Z-B, Song Y-P, Han ZC. Safety of mesenchymal stem cells for clinical application. Stem Cells Int. 2012;2012:652034.

30. Rosenfeld S, Follmann D, Nunez O, Young NS. Antithymocyte globulin and cyclosporine for severe aplastic anemia: association between hematologic response and long-term outcome. JAMA. 2003;289(9):1130-5.

31. Zangi L, Margalit R, Reich-Zeliger S, Bachar-Lustig E, Beilhack A, Negrin R, et al. Direct imaging of immune rejection and memory induction by allogeneic mesenchymal stromal cells. Stem Cells. 2009;27(11):2865-74.

32. Ankrum JA, Ong JF, Karp JM. Mesenchymal stem cells: immune evasive, not immune privileged. Nat Biotechnol. 2014;32(3):252-60.

\section{Publisher's Note}

Springer Nature remains neutral with regard to jurisdictional claims in published maps and institutional affiliations.
Ready to submit your research? Choose BMC and benefit from:

- fast, convenient online submission

- thorough peer review by experienced researchers in your field

- rapid publication on acceptance

- support for research data, including large and complex data types

- gold Open Access which fosters wider collaboration and increased citations

- maximum visibility for your research: over $100 \mathrm{M}$ website views per year

At BMC, research is always in progress.

Learn more biomedcentral.com/submissions 